\title{
Fiscal and monetary policy in a basic endogenous growth model
}

\author{
Alfred Greiner
}




\title{
Fiscal and monetary policy in a basic endogenous growth model
}

\author{
Alfred Greiner*
}

\begin{abstract}
We present a monetary endogenous growth model and analyze the effects of fiscal and monetary policy with real money as an argument in the utility function. We show that a balanced government budget gives a higher balanced growth rate and lower inflation than a situation with permanent public deficits. It also leads to higher welfare compared to a situation with permanent deficits where the government does not put a high weight on stabilizing debt. However, when governments run deficits with a high weight on stabilizing debt, comparative welfare effects depend on the initial conditions with respect to public debt. Further, for a given monetary policy a stricter debt policy yields higher growth, lower inflation and higher welfare. A rise in the nominal money supply can compensate the negative growh effects of a loose debt policy up to a certain point but only at the cost of higher inflation and lower welfare.
\end{abstract}

JEL: H63, E62, E52, O42

Keywords: Public debt, monetary policy, inter-temporal budget constraint, economic growth

*Department of Business Administration and Economics, Bielefeld University, P.O. Box 100131, 33501 Bielefeld, Germany. 


\section{Introduction}

In the aftermath of the financial crisis governments had run excessive public deficits to support the financial sector in their economies. Particularly in some euro countries, this brought about extremely high debt to GDP ratios endangering the stability of the whole euro zone. The European Union reacted to that threat by creating the European Stability Mechanism that supports highly indebted countries. Simultaneously, the European Central Bank, just as other central banks in the world, expanded its money supply to assist both the financial sector and governments.

With this contribution we intend to contribute to the research dealing with the question of how the interplay between public debt policy and monetary policy affects growth, inflation and welfare of economies. Among other things, we want to see whether central banks can compensate loose debt policies of governments by a higher growth rate of nominal money supply. It is well known that in endogenous growth models without money, higher debt to GDP ratios go along with lower growth in the long-run. ${ }^{1}$ This holds both for the case of productive public spending (cf. Greiner, 2008, 2012) as well as for the case when government spending is unproductive (see Greiner, 2011). Only when imperfect labour markets are allowed for, giving rise to permanent unemployment, public debt does not affect the allocation of resources (see Greiner, 2012a) so that raising public deficits to finance productive public investment can lead to a higher balanced growth rate (cf. Greiner and Flaschel, 2010).

When a monetary sector is to be integrated in endogenous growth models the question of arises how that can be achieved. In economics, usually three approaches can be found (for a survey see Wang and Yip, 1992). First, there is the so-called money-in-theutility-function approach that assumes that real money holdings have a positive effect on the utility of agents. The second way of integrating real money is the cash-in-advance

\footnotetext{
${ }^{1}$ For an extensive survey of both empirical and theoretical studies dealing with the effects of public debt on growth, see e.g. Panizza and Presbitero (2013).
} 
approach that posits that consumption goods and a part of the investment goods must be purchased out of existing real money balances. The third approach, finally, is the transactions-costs approach where money is introduced through a shopping-time technology that states that the time spent for shopping is the smaller the higher the real money holdings are. Resorting to those approaches, the interaction between monetary and fiscal policy can be studied then. ${ }^{2}$

There also exist studies dealing with money in endogenous growth models. For example, Jones and Manuelli (1995) analyse different types and show that in some models of endogenous growth inflation has direct effects on the growth rate of the economy by distorting the choice of households between consumption and leisure. That effects also characterizes the models presented by Wu and Zhang (1998) and by Gomme (1993). There, a rise in the inflation rate reduces the level of employment, thus, leading to lower growth. Gillman and Kejak (2005) set up a nesting model in order to analyze the theoretical literature on inflation and endogenous growth. They can show that a large array of models can all generate negative effects of inflation on economic growth. Further, they point out that the models can be distinguished whether there is a nonlinear relationship between inflation and growth so that the effect becomes smaller as inflation rises, or, whether this relation remains constant over the range of inflation rates.

In this paper we adopt the money-in-the-utility approach and assume that real money holding yields utility for the representative household. Sustained growth in our model is the result of positive externalities leading to constant returns to capital in the economy. We can show for our model that a balanced government budget always gives rise to a higher balanced growth rate compared to an economy with permanent public deficits. That also holds with respect to welfare unless governments put a high weight on stabilizing public debt when running permanent deficits. In that case, welfare effects of the balanced

\footnotetext{
${ }^{2}$ See for example Piergallini and Rodano (2012) who also present a good survey of such analyses for models characterized by exogenous growth.
} 
budget scenario compared to the scenario with permanent deficits depend on the initial conditions with respect to public debt. When governments run permanent deficits, a more strict debt policy implies higher long-run growth as well as higher welfare. Further, the central bank can compensate a loose debt policy by increasing the nominal money growth rate. Such a policy raises the long-run growth rate but goes a along with higher inflation and less welfare. In addition, that is possible only up to a certain point, meaning that sustained growth is not feasible once the debt policy of the government falls short of a critical value.

In the rest of the paper we proceed as follows. In the next section we present the structure of our growth model. Section 3 analyzes our model where we study growth and welfare effects of different debt and monetary policies and section 4, finally, summarizes the main results and concludes the paper.

\section{The monetary growth model}

The economy we analyze consists of a household sector, of a productive sector and of the public sector. The latter is composed of the government that collects taxes and runs into public debt to finance its spending and of the central bank that determines nominal money growth. First, we describe the household sector.

\subsection{The household sector}

The household sector consists of many identical households of mass one where each household has measure zero. One household is representative for the whole household sector and maximizes the discounted stream of utility arising from real consumption, $c(t)$, from real money holdings, $m(t)$, and it has disutility from working with $l(t)$ denoting labour supply. ${ }^{3}$ The utility function is assumed to be logarithime and the household maximizes

\footnotetext{
${ }^{3}$ In the following we delete the time argument $t$ as long as no unambiguity arises.
} 
its utility over an infinite time horizon subject to its budget constraint, taking factor prices as given. Thus, the maximization problem of the household can be written as

$$
\max _{c, l} \int_{0}^{\infty} e^{-\rho t}\left(\ln c+\ln m-l^{1+\gamma} /(1+\gamma)\right) d t
$$

subject to

$$
c+\dot{a}+\dot{m}=(1-\tau)(w l+r a)+t_{p} y-\pi m .
$$

The parameter $\rho \in(0,1)$ is the rate of time preference and $\gamma \geq 0$ gives the inverse of the elasticity of labour supply. The variable $a$ denotes the assets of the household that are composed of real capital, $k$, where we neglect depreciation, and of real government bonds, $b$, and $m$ stands for real money holdings. The income tax rate is denoted by $\tau \in(0,1)$ and $w$ and $r$ gives the real wage rate and the real interest rate, respectively. Finally, $t_{p} \in(0, \tau)$, gives lump-sum transfers as a share of real GDP, $y$, and $\pi$ stands for the inflation rate. It should be mentioned that we do not consider negative transfers that would imply an additional tax for the hosuehold and that the transfer share is smaller than the tax rate.

We should like to point out that the budget constraint in real terms is derived from the nominal budget constraint, $P c+P \dot{k}+\dot{M}+\dot{B}=(w l+r k) P(1-\tau)+i B-\tau(i-\pi) B+t_{p} Y$, with $P$ the price level, $i=r+\pi$ the nominal interest rate and capital letters denoting nominal variables. This implies that the government only taxes the real return to government bonds which must hold for one unit of physical capital to yield the same return as one unit of government bonds in real terms. This is a no-arbitrage condition that makes the household indifferent between investing in physical capital and in government bonds.

To solve this problem we formulate the current-value Hamiltonian which is written as $\mathcal{H}=\left(\ln c+\ln m-l^{1+\gamma} /(1+\gamma)\right)+\lambda_{1}\left((1-\tau)(w l+r a)+t_{p} y-\pi m-c\right)+\lambda_{2}(s-a-m)$,

with $\lambda_{1}$ the shadow price of private savings, $s$, and $\lambda_{2}$ a Lagrange multiplier. The necessary 
optimality conditions are obtained as,

$$
\begin{aligned}
c^{-1} & =\lambda_{1} \\
l^{\gamma} & =\lambda_{1} w(1-\tau) \\
\dot{\lambda}_{1} & =\rho \lambda_{1}-\lambda_{2} .
\end{aligned}
$$

In addition, the return to assets must equal the value of money holdings at the margin, implying the following two conditions,

$$
\begin{aligned}
& \lambda_{2}=\lambda_{1} r(1-\tau) \\
& \lambda_{2}=m^{-1}-\lambda_{1} \pi .
\end{aligned}
$$

Combining equations (4)-(8) leads to the following conditions that characterize an optimum,

$$
\begin{aligned}
c & =m((1-\tau) r+\pi) \\
l^{\gamma} & =w(1-\tau) c^{-1} \\
\dot{c} & =c((1-\tau) r-\rho)
\end{aligned}
$$

If the transversality condition $\lim _{t \rightarrow \infty} e^{-\rho t} s / c=0$ holds, which is the standard household's no-Ponzi game condition, that is fulfilled for a time path on which savings grow at the same rate as consumption, the necessary conditions are also sufficient.

\subsection{The productive sector}

The productive sector is represented by one firm which behaves competitively and which maximizes static profits. The production function of the firm is given by,

$$
y=A k^{1-\alpha} \bar{k}^{\xi} l^{\alpha}
$$

with $(1-\alpha) \in(0,1)$ the capital share and $\alpha \in(0,1)$ the labour share, $y$ real output and $\bar{k}$ represents the average economy-wide level of capital. The parameter $A>0$ reflects total productivity and we assume constant returns to capital in the economy, i.e. $(1-\alpha)+\xi=1$. 
Using $(1-\alpha)+\xi=1$ and that $k=\bar{k}$ in equilibrium, profit maximization gives the real interest rate and the real wage rate as

$$
\begin{aligned}
r & =(1-\alpha) A l^{\alpha} \\
w & =\alpha A l^{\alpha-1} k
\end{aligned}
$$

\subsection{The public sector}

The government in our economy receives tax revenues from income taxation and has revenues from issuing government bonds it uses to finance lump-sum transfers, $p=t_{p} y$, and public spending that is neither welfare enhancing nor productive. The period budget constraint of the government describing the accumulation of public debt in real terms is given by,

$$
\dot{b}+\dot{m}=r b(1-\tau)-p s-\pi m
$$

where $p s$ is the real primary surplus, i.e. government surplus exclusive of net interest payments.

The inter-temporal budget constraint of the government is fulfilled if

$$
\lim _{t \rightarrow \infty} P_{0} e^{-\int_{0}^{t}(1-\tau) r(\mu) d \mu} b(t)=0
$$

holds with $P_{0}$ the price level at $t=0$ which is set equal to one.

With respect to the primary surplus, we assume that the government sets the primary surplus according to the following rule,

$$
p s=\phi y+\beta b \text {. }
$$

The parameter $\beta \in \mathbb{R}_{++}$determines how strong the primary surplus reacts to changes in public debt and will be denoted as the reaction coefficient and $\phi \in \mathbb{R}$ determines whether the level of the primary surplus rises or falls with an increase in GDP. The motivation for that rule is that it guarantees that the time series of public debt becomes a 
mean-reverting process such that the inter-temporal budget constraint of the government is fulfilled (see e.g. Greiner, 2008, 2011). Further, one finds very strong evidence that governments do indeed act as if they followed that rule. For example, Bohn (1998) and Greiner et al. (2007) have shown that this rule holds for the USA and for selected euro area countries, respectively, using OLS estimations. Allowing for modern non-parametric estimation techniques, Fincke and Greiner (2011, 2011a) also find that the average of the reaction coefficient, determining the response of the primary surplus to public debt, is strictly positive for most countries.

The monetary authority determines the growth rate of the money supply by setting the parameter $\theta>0$ that gives the growth rate of nominal money supply, $M$. Thus, real money supply is determined as,

$$
\frac{\dot{m}}{m}=\frac{\dot{M}}{M}-\pi=\theta-\pi
$$

In the next subsection we define equilibrium conditions and the balanced growth path.

\subsection{The balanced growth path}

The economy-wide resource constraint for our economy is obtained by combining the budget constraint of the household, equation (2), with that of the government, equation (15), as,

$$
\dot{k}=y(1-\tau+\phi)-c+t_{p} y+\beta b,
$$

where the primary surplus rule (17) has been used and $y$ has been obtained from equation (12) as $y=k A^{(1+\gamma) /(1-\alpha+\gamma)}((k / c) \alpha(1-\tau))^{\alpha /(1-\alpha+\gamma)}$, where $k=\bar{k}$ has been used. Using the opimality conditions determining the factor prices, equations (13) and (14), the evolution of private consumption is described by,

$$
\dot{c}=c((1-\tau)(1-\alpha)(y / k)-\rho)
$$


Given the primary surplus rule (17), the evolution of public debt is obtained from (15) as follows,

$$
\dot{b}=(1-\tau)(1-\alpha) b(y / k)-\theta m-\phi y-\beta b
$$

and the growth of real money supply is given by

$$
\dot{m}=m \theta-c+m(1-\tau)(1-\alpha)(y / k)
$$

with the inflation rate $\pi$ determined by equation (9). Thus, in equilibrium the economy is completely described by the four differential equations (19)-(22).

We are interested in a situation with permanent growth. Therefore, we define a balanced growth path (BGP) as a path on which all economic variables grow at the same constant rate, possibly with the exception of public debt. As concerns public debt we consider two scenarios: Either, the government budget is balanced such that public debt is constant or the government runs permanent deficits such that public debt grows at the same rate as all other economic variables on the BGP.

To analyze our economy around a BGP we define the following variables, $x:=c / k$, $z:=m / k$ and $v:=b / k$. The differential equation system that describes our economy around a BGP, then, is obtained as,

$$
\begin{aligned}
& \dot{x}=x\left((1-\tau)(1-\alpha)(y / k)-\rho-(y / k)\left(1-\tau+\phi+t_{p}\right)+x-\beta v\right), \\
& \dot{z}=z\left(\theta-x / z+(1-\tau)(1-\alpha)(y / k)-(y / k)\left(1-\tau+\phi+t_{p}\right)+x-\beta v\right), \\
& \dot{v}=v\left(x-\theta(z / v)-\phi v^{-1}(y / k)-\beta-(y / k)\left(\alpha(1-\tau)+\phi+t_{p}\right)-\beta v\right),
\end{aligned}
$$

with $y / k$ given by $y / k=A^{(1+\gamma) /(1-\alpha+\gamma)} x^{-\alpha /(1-\alpha+\gamma)}(\alpha(1-\tau))^{\alpha /(1-\alpha+\gamma)}$. A rest point of (23)-(25) yields a BGP which implies $g:=\dot{c} / c=\dot{m} / m=\dot{k} / k, \dot{b}=0, v^{\star}=0$, for a balanced government budget ${ }^{4}$ and $g=\dot{c} / c=\dot{m} / m=\dot{k} / k=\dot{b} / b$ with permanent public deficits.

In the next section we analyze our model with respect to growth and welfare effects of different fiscal policy scenarios.

\footnotetext{
${ }^{4} \mathrm{The}^{\star}$ denotes BGP values.
} 


\section{Analysis of the model}

First, we analyze our model with respect to existence and stability of a BGP and we study growth effects of fiscal and monetary policy.

\subsection{Analyzing the structure of the model and growth effects}

To start with we consider the balanced budget scenario and compare it to the scenario with permanent public deficits.

\subsubsection{The balanced budget scenario}

A balanced budget means $\dot{b}=0$ which implies $\phi=-\theta z(k / y)$, where $v^{\star}=0$ has been used. Further, $\dot{c} / c=\dot{m} / m$ implies $z=x /(\rho+\theta)$. Using those relations we get for $q_{1}(\cdot):=\dot{x}$,

$$
q_{1}=x\left(x-\left(x^{-1} A^{(1+\gamma) / \alpha} \alpha(1-\tau)\right)^{\alpha /(1-\alpha+\gamma)}\left(t_{p}+\alpha(1-\tau)\right)+\theta x(\theta+\rho)^{-1}-\rho\right) .
$$

It is easily seen that $q_{1}(\cdot)$ is continuous and has the following properties, $q_{1} \rightarrow-\infty(+\infty)$ for $x \rightarrow 0(\infty)$, and $\partial q_{1} / \partial x>0$ for $\dot{x}=0$. This shows that there exists a unique $x^{\star}$ that solves $\dot{x}=0$ and, thus, a unique BGP for the balanced budget scenario.

The local stability of the dynamic system is determined by the eigenvalues of the Jacobian matrix corresponding to the system (23)-(25). In the appendix it is demonstrated that the Jacobian has one negative eigenvalue implying that there is a one-dimensional stable manifold of the dynamic system. Taking the initial capital stock and the initial public debt as given, this implies that there exists a unique value of initial consumption, $c(0)$, and of the initial stock of money, $m(0)$, such that the economy converges to the BGP in the long-run.

Another analytical result can be obtained for the long-run growth rate of the balanced budget scenario compared to that of the scenario with permanent public deficits. To do so, we note that for the balanced budget scenario we get from $\dot{c} / c=\dot{k} / k$ on the BGP,

$$
-\rho+(1-\tau)(1-\alpha)(y / k)=-x+\left(1-\tau+t_{p}\right) x^{-\alpha /(1-\alpha+\gamma)} C_{1}-\theta x /(\theta+\rho),
$$


where used $z=x /(\theta+\rho)$ and with $C_{1}:=A^{(1+\gamma) /(1-\alpha+\gamma)}(\alpha(1-\tau))^{\alpha /(1-\alpha+\gamma)}$. In addition, we used $\phi=-\theta z x^{\alpha /(1-\alpha+\gamma)} C_{1}$ that holds for a balanced government budget.

With permanent public deficits we obtain from $\dot{c} / c=\dot{k} / k$ on the BGP,

$$
-\rho+(1-\tau)(1-\alpha)(y / k)=-x+\left(1-\tau+t_{p}\right) x^{-\alpha /(1-\alpha+\gamma)} C_{1}+\beta v+\phi x^{-\alpha /(1-\alpha+\gamma)} C_{1} .
$$

From $\dot{c} / c=\dot{b} / b$ that must also hold on the BGP we get,

$$
\beta v+\phi x^{-\alpha /(1-\alpha+\gamma)} C_{1}=-\theta z+\rho v
$$

so that (28) can be rewritten as,

$$
-\rho+(1-\tau)(1-\alpha)(y / k)=-x+\left(1-\tau+t_{p}\right) x^{-\alpha /(1-\alpha+\gamma)} C_{1}-\theta x /(\theta+\rho)+\rho v .
$$

Comparing equation (27) with (30) shows that the left hand side is identical in both equations and monotonically rising with $x$. The right hand side in those two equations is monotonically declining with the graph of equation (30) always above that of (27), because of $v>0$, which implies that the consumption share on the BGP, $x^{\star}$, with permanent deficits is larger than the consumption share with a balanced government budget. Consequently, the balanced growth rate in the scenario with permanent deficits is lower than that of the balanced budget scenario.

Next, we analyze our model with permanent public deficits.

\subsubsection{Permanent public deficits}

When we consider the model with permanent public deficits we see that it becomes rather complex such that we cannot gain analytical results. Therefore, we resort to simulations in order to gain insight into our model economy.

To do so we first specify the structural parameters of our model and the income tax rate as well as the share of lump-sum transfers. We set the labour share to 70 percent, i.e. $\alpha=0.7$, and $A$ is set to $A=0.3$. The rate of ime preference is asumed to be 5 percent, $\rho=0.05$. As concerns the inverse of the elasticity of labour supply, values between 0.15 
and 0.3 are considered as plausible (see e.g. Benhabib and Farmer, 1994) and we choose $\gamma=0.3$. The income tax rate is 10 percent, $\tau=0.1$, and the share of lump-sum transfers is set to $t_{p}=0.075$. Those parameters are left unchanged throughout our simulations. ${ }^{5}$

To start with we study how public debt policy affects economic growth for a given monetary policy. Table 1 shows how the balanced growth rate, the debt to capital ratio and the inflation rate react when the government reduces the reaction coefficient $\beta$, that is when it puts less weight on stabilizing public debt, where the growth rate of nominal money supply is set to $\theta=0.07$ and $\phi=-0.33$.

Table 1: The growth rate, $g$, the debt to capital ratio, $v$, and the inflation rate, $\pi$, for different values of the reaction coefficient, $\beta$, on the BGP.

\begin{tabular}{c|ccc}
$\beta$ & $g$ & $v$ & $\pi$ \\
\hline \hline 0.1 & $3.72 \%$ & 0.0625 & $3.28 \%$ \\
0.075 & $3.69 \%$ & 0.0966 & $3.31 \%$ \\
0.05 & $3.58 \%$ & 0.2126 & $3.42 \%$ \\
0.035 & $3.09 \%$ & 0.7682 & $3.91 \%$ \\
\hline
\end{tabular}

Table 1 demonstrates that the balanced growth rate declines as the government puts less weight on stabilizing public debt, that is when it reduces the reaction coefficient $\beta$, which implies a higher debt to capital ratio. The economic mechanism behind that result is that a less strict public debt policy implies that less savings of the private sector are used for private capital formation but, instead, for unprodutive public spending. This makes the household save and invest less and reduce its labour supply, thus, leading to a lower growth rate in the long-run. Table 1 also shows that a less strict debt policy leads to a

\footnotetext{
${ }^{5}$ Qualitatively, the outcome does not change for $\gamma=0.15$. But to get plausible quantitative results we have to set $A$ and the fiscal parameters $\tau$ and $t_{p}$ to different values then.
} 
higher inflation rate. That holds because the decline in the investment share implies a rise in the consumption share that goes along with higher inflation. With the parameter values underlying table 1 the Jacobian matrix of the dynamic system (23)-(25) has one negative and two positive real eigenavlues. Thus, there exists a unique combination $\{c(0), m(0)\}$ such that the economy converges to the BGP in the long-run.

When we further reduce the reaction coefficient $\beta$, we see that for about $\beta \leq 0.03$ no BGP exists any longer or there exists a BGP that, however, goes along with a negative government debt and that is unstable, i.e. the Jacobian has three positive real eigenvalues. This implies that ongoing growth is not possible if the government puts too low a value on stabilizing public debt or only in case the government is a creditor that lends money to the private sector. But it must also be pointed out that the latter situation is unstable which means that the economy cannot reach that BGP unless it starts on the BGP at the beginning.

These considerations demonstrate that a less strict public debt policy leads to a lower balanced growth rate, to a higher debt ratio and to higher inflation, for a given monetary policy. In addition, if the public debt policy is too loose sustained growth may not be feasible at all with the government being a debtor. The question we address next is how monetary policy affects growth and whether it can compensate a loose debt policy. Table 2 gives the results of varying the nominal money growth rate $\theta$ with $\beta=0.1$ and the other parameter values as for table 1 . 
Table 2: The growth rate, $g$, the debt to capital ratio, $v$, and the inflation rate, $\pi$, for different values of the nominal money growth rate, $\theta$, on the BGP.

\begin{tabular}{c|ccc}
$\theta$ & $g$ & $v$ & $\pi$ \\
\hline \hline 0.025 & $2.49 \%$ & 0.4821 & $0.01 \%$ \\
0.05 & $3.33 \%$ & 0.1894 & $1.67 \%$ \\
0.075 & $3.8 \%$ & 0.0384 & $3.7 \%$ \\
0.08 & $3.87 \%$ & 0.0164 & $4.13 \%$ \\
\hline
\end{tabular}

Table 2 illustrates the following. A higher growth rate of the money supply leads to a lower debt to capital ratio and to a higher balanced growth rate. However, that goes at the cost of higher inflation that monotonically rises when the money supply is increased. It must also be pointed out that this cannot go on forever. Hence, once a certain critical value of $\theta$ is exceeded, in our example for about $\theta \geq 0.85$, a balanced growth path with the government being a debtor does not exists any longer. Then, for ongoing growth to be feasible, the government must be a creditor.

Thus, we can conclude that monetary policy can compensate a loose debt policy of the government, but only up to a certain point. When the nominal money growth rate becomes too large, sustained growth is not possible unless the government disposes of a capital reserve it uses to lend money to the private sector. For the sake of completeness, we state that the stability properties of the system (23)-(25) with the parameter values underlying table 2 are identical to those in table 1, i.e. the Jacobian has one negative and two positive real eigenvalues.

In table 2 we have seen allocative effects of monetary policy for the case that the government runs permanent deficits. In the following table we show how variations in the nominal money growth rate affects the balanced growth rate and the inflation rate 
assuming that the government runs a balanced budget that implies a zero debt to capital ratio in the long-run.

Table 3: The growth rate, $g$, the debt to capital ratio, $v$, and the inflation rate, $\pi$, for different nominal money growth rates, $\theta$, on the BGP with a balanced government budget.

\begin{tabular}{c|ccc}
$\theta$ & $g$ & $v$ & $\pi$ \\
\hline \hline 0.035 & $3.2 \%$ & 0 & $0.03 \%$ \\
0.07 & $3.22 \%$ & 0 & $3.78 \%$ \\
0.1 & $4.05 \%$ & 0 & $5.95 \%$ \\
0.15 & $4.58 \%$ & 0 & $20.42 \%$ \\
\hline
\end{tabular}

Table 3 shows that a higher nominal money growth rate goes along with a higher balanced growth rate that, however, implies higher inflation as in table 2. Further, the increase in the inflation rate is rather drastic and the rise is faster than that of the balanced growth rate. Setting $\theta=0.5$ implies an inflation rate of 45 percent while the growth rate only attains a value of 4.8 percent. Due to the balanced government budget the debt to capital ratio does not change with variations in the monetary policy and always equals zero. Thus, with a balanced government budget the economy can attain a higher long-run growth rate through appropriate monetary policy. But, such a policy goes at the expense of price stability and the question of arises whether such a policy is also welfare enhancing.

Therefore, in the next subsection we study welfare effects of public debt policy and of monetary policy for our model economy.

\subsection{Welfare effects}

In the last subsection we have seen how fiscal and monetary policy affect the allocation of resources and, thus, economic growth and inflation. In this subsection we want to analyze 
whether welfare reacts to policy measures in the same way as the balanced growth rate. To do so we solve the linearized differential equation system (23)-(25), taking into account transition dynamics, that gives the time paths for the variables $x(t), z(t)$ and $v(t)$ for a given value of initial public debt relative to capital, $v_{0}$. With these variables we can solve the differential equations (20) and (22), where we set $K_{0}=1$ such that $x(0)=c(0)$ and $z(0)=m(0)$ and we get the time path for labour supply $l(t)$. Then, we can compute the value of the utility functional (1) that gives welfare in our economy for a given policy as,

$$
J_{1} \equiv \max \int_{0}^{\infty} e^{-\rho t}\left(\ln c+\ln m-l^{1+\gamma} /(1+\gamma)\right) d t .
$$

The last result of the previous subsection was that a higher nominal money growth leads to a higher balanced growth rate but also to higher inflation in the case of a balanced government budget. ${ }^{6}$ Table 4 shows how welfare reacts to such a monetary policy.

Table 4: Welfare, $J_{1}$, for different nominal money growth rates, $\theta$, with a balanced government budget.

\begin{tabular}{c||ccc}
$\theta$ & 0.035 & 0.05 & 0.1 \\
\hline$J_{1}$ & -6.875 & -9.998 & -17.854
\end{tabular}

From table 4 we see that a higher growth rate of nominal money supply reduces welfare. There are the following opposite effects of such a monetary policy. On the one hand, raising the nominal money growth increases the balanced growth rate and leads to higher consumption that tends to raise welfare. However, on the other hand, a high inflation rate reduces the real money stock and a large growth rate implies a high labour supply. Those two latter effects dominate and make welfare decline as a result of a higher growth rate of nominal money supply.

\footnotetext{
${ }^{6}$ The initial condition of $v$ is set to $v_{0}=0.5$ for the simluations in tables $4-6$. The qualitative outcome in those tables, however, is independent from $v_{0}$ anyway.
} 
Next, we analyze welfare effects of monetary policy assuming that the government does not run a balanced budget. From table 2 we know that in this case a higher growth rate of nominal money supply leads to higher growth and to higher inflation. The results are shown in table 5 , with $\beta=0.1$.

Table 5: Welfare, $J_{1}$, for different values of the nominal money growth rate, $\theta$.

\begin{tabular}{c||ccc}
$\theta$ & 0.035 & 0.05 & 0.07 \\
\hline$J_{1}$ & -6.978 & -9.269 & -12.097
\end{tabular}

The outcome is equivalent to that in table 4, that is the negative welfare effect of higher inflation and of a higher labour supply dominate the positive welfare effect of higher consumption growth as a result of increasing the nominal money supply. These outcomes demonstrate that a rise in the growth rate of nominal money supply raises the balanced growth rate but leads to lower welfare.

When we analyze how different debt policies affect welfare we see that a higher reaction coefficient $\beta$ leads to higher welfare as table 6 demonstrates, where we set the nominal money growth rate to $\theta=0.07$. The reason for that outcome is that a stricter fiscal policy, in the sense that the government puts a higher weight on stabilizing public debt by setting the reaction coefficient $\beta$ to a large value, generates a higher growth rate, a lower inflation rate and a higher labour supply. The first two effects raise welfare while the third leads to less welfare which, however, is dominated by the first two positive welfare effects.

Table 6: Welfare, $J_{1}$, for different values of the reaction coefficient, $\beta$.

\begin{tabular}{c||ccc}
$\beta$ & 0.035 & 0.05 & 0.1 \\
\hline$J_{1}$ & -14.953 & -14.122 & -12.097
\end{tabular}


The last exercise we perform is a comparison of welfare of the scenario with a balanced government debt and of the scenario with permanent deficits for different initial conditions with respect to public debt and for different reaction coefficients $\beta$. Table 7 shows the results with $\theta$ set to $\theta=0.07$.

Table 7: Welfare, $J_{1}$, for a balanced government budget compared to permanent deficits.

\begin{tabular}{l||cccl} 
& $v_{0}=0.05$ & $v_{0}=0.5$ & $v_{0}=1$ & \\
\hline$J_{1}$ & -14.513 & -13.519 & -12.491 & (balanced gov. budget) \\
$J_{1}$ & -15.02 & -14.122 & -13.19 & (perm. deficits, $\beta=0.05)$ \\
$J_{1}$ & -14.723 & -12.097 & -9.484 & (perm. deficits, $\beta=0.1$ )
\end{tabular}

Table 7 demonstrates that the balanced budget scenario always yields higher welfare than the scenario with permanent deficits for small values of the reaction coefficient, independent of the initial conditions. That is, when the government puts a small weight on stabilizing public debt, a balanced government budget leads to higher welfare. That general result does not hold any longer when the government runs permanent deficits but puts a high weight on stabilizing debt, i.e. when it selects a high $\beta$. Then, the debt ratio is relatively small so that its negative effects (low growth, high inflation) are not too large. In that situation, the outcome depends on the initial conditions and for high values of the initial stock of public debt, the scenario with permanent deficits gives higher welfare than the balanced budget scenario. Only if the initial public debt is small, the balanced budget scenario performs better. The reason for that outcome is that with a high initial debt, the initial values of consumption and of the real money supply are clearly higher so that the time paths of consumption and of real money are above those obtained for smaller initial values of public debt. Therefore, a scenario where the government runs deficits but puts a high weight on stabilizing debt, so that the debt ratio and its negative 
effects are small, can perform better when the economy is relatively far away from its balanced growth path.

\section{Conclusion}

In this paper we have analyzed a basic monetary endogenous growth model where real money is an argument in the utility function. Analyzing fiscal and monetary policies we could show the following.

1. A balanced budget always implies a higher gowth rate in the long-run compared to a scenario with permanent deficits. A balanced budget also yields higher welfare than a scenario with permanent deficits if the government puts little weight on stabilizing public debt since the latter implies a high debt to GDP ratio leading to low growth and high inflation. If the government puts a high weight on stabilizing debt in the deficit scenario this may change. Then, the debt to GDP ratio is relatively small such that the negative effects of public debt (low growth, high inflation) are not too drastic. In such a situation, a scenario with permanent debt can lead to higher welfare than the balanced budget scenario if the initial debt to GDP ratio is large so that it is far away from its value on the balanced growth path. However, if the initial debt ratio is small, a balanced government budget still goes along with higher welfare.

2. For a given monetary policy in the scenario with permanent public deficits, lower deficits implying smaller debt ratios lead to higher balanced growth and less inflation. Further, if the reaction coefficient is below a certain threshold, sustained growth is not feasible any longer unless the government is a creditor and lends money to the private sector. A more strict debt policy leading to lower debt ratios also generates higher welfare.

3. For a given public debt policy, raising the nominal money growth rate leads to higher balanced growth and to higher inflation. Thus, the monetary policy can compensate a loose public debt policy. However, it must be underlined that this only holds up to a certain degree. Thus, if the nominal monetary growth rate exceeds a certain threshold 
sustained growth is not feasible or only if the government is a again a creditor. But a higher nominal money growth rate reduces welfare because the positive welfare effect of higher consumption growth is compensated by the negative welfare effect of higher inflation and of higher labour supply.

Hence, the overall conclusion we can draw from this paper is that a stricter debt policy implies both higher growth in the long-run and also higher welfare, in general. The monetary policy can compensate a loose fiscal policy, but only up to a certain point, and it must also be underlined that a higher nominal money growth leads to lower welfare.

\section{Appendix}

\section{Stability of the balanced budget scenario}

With a balanced government budget that implies $\phi=-\theta z(k / y)$, the Jacobian of the dynamic system (23)-(25) is given by,

$$
J=\left[\begin{array}{ccc}
\partial \dot{x} / \partial x & \theta x & -\beta x \\
\partial \dot{z} / \partial x & (\theta+\rho+\theta z) & -\beta z \\
0 & 0 & -g
\end{array}\right]
$$

where we also used $\dot{v}=-v(\partial \dot{k} / \partial k), x^{\star} / z^{\star}=\theta+\rho$ and $v^{\star}=0$ on the BGP and the variables $x$ and $z$ are evaluated at the BGP. Since $\partial \dot{x} / \partial x=x C_{2}$ and $\partial \dot{z} / \partial x=z C_{2}-1$, with $C_{2}=\partial(\dot{x} / x) / \partial x>0$, we get $(\partial \dot{x} / \partial x)(\theta+\rho+\theta z)-\theta x(\partial \dot{z} / \partial x)=x C_{2}(\theta+\rho)+\theta x>0$ as well as $(\partial \dot{x} / \partial x)+(\theta+\rho+\theta z)>0$, so that there exists one negative eigenvalue of $J$ given by $-g$.

\section{References}

Benhabib, J., and R. Farmer (1994), 'Indeterminacy and Increasing Returns', Journal of Economic Theory 63, 19-41. 
Bohn, H. (1998), 'The behaviour of U.S. public debt and deficits', Quarterly Journal of Economics 113, 949-63.

7, 827-40.

Fincke, B. and A. Greiner (2011) "Do large industrialized economies pursue sustainable debt policies? A comparative study for Japan, Germany and the United States." Japan and the World Economy, Vol. 23: 202-213.

Fincke, B. and A. Greiner (2011a) "Debt sustainability in selected euro area countries. Empirical evidence estimating time-varying parameters." Studies in Nonlinear Dynamics \& Econometrics, Vol. 15, no. 3, article 2.

Gillman, M. and M. Kejak (2005) 'Contrasting Models of the effect of inflation on growth', Journal of Economic Surveys, 19, 113-36.

Gomme, P. (1993) 'Money and growth revisited: Measuring the costs of inflation in an endogenous growth model', Journal of Monetary Economics, 32, 51-77.

Greiner, A. (2008), 'Does it pay to have a balanced government budget?', Journal of Institutional and Theoretical Economics 164, 460-76.

Greiner, A. (2011) 'Economic growth, public debt and welfare: Comparing three budgetary rules', German Economic Review, 12, 205-22.

Greiner, A. (2012) 'Human capital formation, learning by doing and the government in the process of economic growth', Scottish Journal of Political Economy, 51, 71-89.

Greiner, A. (2012a) 'Sustainable public debt and economic growth under wage rigidity', Metroeconomica, first published online: 22 NOV 2012, DOI: 10.1111/meca.12006

Greiner, A. and P. Flaschel (2010) 'Public debt and public investment in an endogenous growth model with real wage rigidities', Scottish Journal of Political Economy, 57, 68-84. 
Greiner, A., U. Köller and W. Semmler (2007) 'Debt sustainability in the European Monetary Union: Theory and empirical evidence for selected countries', Oxford Economic Papers, 59, 194-218.

Jones, L.E., and R.E. Manuelli (1995) 'Growth and the effects of inflation', Journal of Economic Dynamics and Control, 19, 1405-28.

Panizza, U. and A.F. Presbitero (2013) 'Public debt and economic growth in advanced economies: A Survey', Money and Finance Research Group, Working paper no. 78.

Piergallini, A. and G. Rodano (2012) 'Public debt, distortionary taxation, and monetary policy', CEIS Tor Vergata, Research Paper Series, 10(2), no. 220.

Wang, P. and C.K. Yip (1992) 'Alternative approaches to money and growth', Journal of Money, Credit and Banking, 24, 553-62.

Wu, Y. and J. Zhang (1998) 'Endogenous growth and the welfare costs of inflation: a reconsideration', Journal of Economic Dynamics and Control, 22, 465-82. 